\title{
Use of food labels and beliefs about diet-disease relationships among university students
}

\author{
Shannon C Smith ${ }^{1}$, Jeffrey G Taylor ${ }^{1}$ and Alison M Stephen ${ }^{1, *}$ \\ ${ }^{1 *}$ College of Pharmacy and Nutrition, University of Saskatchewan, 110 Science Place, Saskatoon, \\ Canada S7N 5C9
}

Submitted 20 February 1999: Accepted 29 June 1999

\begin{abstract}
Objective: The purpose of this study was to measure the reported use of nutrition information on food labels by a population of university students and to determine if label users differed from non-users in terms of gender and specific beliefs related to label information and diet-disease relationships, specifically fat and heart disease and fibre and cancer.

Design: A single-stage cluster sampling technique was used. Data was obtained using a self-administered, validated questionnaire.

Setting: The present investigation took place at the University of Saskatchewan, Canada in the autumn of 1997.

Subjects: A total of 553 students in randomly selected classes in the College of Arts and Science took part in the survey ( $92 \%$ response rate). The sample consisted of roughly equal numbers of males and females, most between the ages of 18 and 24 .

Results: There were approximately equal numbers of label users and non-users among males, while label users outnumbered non-users by almost four to one among females. The importance of nutrition information on food labels was the only belief that differed significantly between label users and non-users for both sexes. For females, no other beliefs distinguished label users from non-users. However, for males, significant differences were found between label users and non-users on the beliefs that nutrition information is truthful and that a relationship between fibre and cancer exists.

Conclusions: Females appear to use food labels more often than do males. The only consistently observed difference between label users and non-users (male and female) was that users believed in the importance of nutrition information on food labels while non-users did not.
\end{abstract}

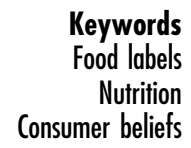

Keywords

Nutrition

Consumer beliefs
Heart disease and cancer are the number one and two killers in North America today ${ }^{1,2}$. Both diseases have been linked to dietary factors, most commonly fat and fibre ${ }^{3}$. As a result, both American and Canadian health authorities have put forth dietary recommendations to the public to provide guidance in the selection of a dietary pattern that will minimize the risk of developing these diseases. To facilitate food choices for consumers, the US government has made nutrition labelling mandatory on most food packaging by means of the Nutrition Labelling and Education Act (NLEA) ${ }^{4}$. Although detailed nutrition information is available on most food packages in the USA, it is disregarded by up to $55 \%$ of Americans ${ }^{5}$.

In Canada, the provision of a nutrition information panel is optional; when present, it must list a set of 'core nutrients': energy, protein, fat and carbohydrate. Other nutrients may be listed as desired. Nutrient content claims and biological role claims are also optional; however, their appearance on food packaging triggers the appearance of the nutrition information panel elsewhere on the label. Foods must meet specific nutrient criteria defined by Health Canada in order to bear a nutrient claim. Health Canada prohibits the use of health claims on food labels under the Food and Drugs Act. Canadians have been found to use available nutrition information on food labels no more or less than Americans ${ }^{6-9}$. It seems that the simple provision of nutrition information on food labels is insufficient to motivate consumers to use that information in making food choices.

Research on food label use conducted to date has focused principally on adult grocery shoppers ${ }^{5,6,9-12}$. No studies have specifically looked at food label use among university students. University students are typically making the transition from having minimal control over their food choices (i.e. living at home where parents make many food decisions) to having principal control (i.e. 
living independently and doing their own grocery shopping and food preparation) and are developing food selection skills and habits that will have long-term health effects. Because of their youth, students may not believe they are at risk of developing chronic diseases and may lack the motivation to choose an eating pattern to minimize these risks. In addition, the university environment may provide an opportunity for nutrition educators to facilitate students in developing healthy lifestyle and eating habits ${ }^{13}$.

Behaviour theories suggest that underlying beliefs salient to the behaviour in question greatly influence whether that behaviour is actually carried out ${ }^{14,15}$. The purpose of the present study was to measure the reported frequency of use of nutrition information on food labels among university students and to determine if beliefs about nutrition information on food labels and the existence of diet-disease relationships distinguishes label users from non-users.

\section{Methods}

\section{Study sample}

A single-stage, cluster sampling technique was used to obtain the study sample. Second year classes were randomly sampled to represent a cross-section of the student body at the University of Saskatchewan, Canada. The target sample size of about 500 students was based on previous research conducted with post-secondary students using survey methodology ${ }^{16-19}$. A total of 25 classes were sampled, of which 17 participated.

\section{Survey instrument}

An original questionnaire was developed with sections measuring the use of nutrition information on food labels when purchasing a food for the first time, beliefs about the importance and perceived truthfulness of nutrition information on food labels, beliefs about the existence of diet-disease relationships, and demographics. Questions to address label use were based on items that appeared in the 1995 Health and Diet Survey ${ }^{20}$; however, response categories were modified to provide more descriptive information of label use frequency.

Respondents were categorized as either 'label users' or 'non-users'. A 'label user' was defined as one who uses either the nutrition information panel or nutrient claims 'about half the time' or more often. A 'label non-user' was defined as one who uses neither the nutrition information panel nor nutrient claims 'about half the time' or more often. Demographic items measured sex, age and degree programme in which each student was registered. Food label use and demographic items were pilot tested with 20 students typical of the study sample. Based on comments and questions of clarification posed by these respondents, some questions were reworded and response options altered. In general, no major changes were made to the questionnaire.
A variation of the Thurstone scale of equal appearing intervals was the method used to measure students' beliefs ${ }^{21-25}$. Five beliefs were defined and multi-item Thurstone scales were constructed to measure them:

1. The importance of nutrition information on food labels when making food choices.

2. The perceived truthfulness of the nutrition information panel.

3. The perceived truthfulness of nutrient claims.

4. The existence of a relationship between fat and heart disease.

5. The existence of a relationship between dietary fibre and cancer.

All the scales had a theoretical range of values from one to seven: a value of one being indicative of a very weak belief in the object-attribute relationship and a value of seven being indicative of a very strong belief.

A 14-day test-retest survey was conducted in two second year classes to determine the reliability of the survey instrument. These classes were chosen for convenience but were considered typical of the study population. A total of 38 students completed the 14-day test-retest survey. Ethics approval for sampling and methods were obtained from the University Advisory Committee on Ethics in Human Experimentation.

\section{Survey administration and data collection}

Data collection took place in the autumn of 1997. The same introduction and background information was given at each administration to provide the same contextual information to all respondents. The survey was voluntary, anonymous and took about $20 \mathrm{~min}$ to complete. Those who had previously completed the

Table 1 Reliability for questionnaire sections as determined by 14 day test-retest surveys $(n=38)$

\begin{tabular}{lcc}
\hline Survey section/questions & $\begin{array}{c}\text { Reliability } \\
\text { estimate }\end{array}$ & $\begin{array}{c}\text { Significance } \\
\text { level }\end{array}$ \\
\hline $\begin{array}{c}\text { Food label use } \\
\text { Use of specific label information }\end{array}$ & rho $=0.79^{*}$ & $P<0.001$ \\
$\begin{array}{c}\text { Beliefs about nutrition information on } \\
\text { food labels } \\
\text { Importance of nutrition information } \\
\text { on food labels in making } \\
\quad \text { food choices }\end{array}$ & $r=0.47 \dagger$ & $P>0.05$ \\
$\begin{array}{c}\text { Truthfulness of nutrition information } \\
\text { panel }\end{array}$ & $r=0.63$ & $P<0.001$ \\
$\begin{array}{c}\text { Truthfulness of nutrient claims } \\
\text { Beliefs about diet-disease } \\
\text { relationships }\end{array}$ & $r=0.65$ & $P<0.001$ \\
$\begin{array}{c}\text { Existence of fat-heart disease } \\
\text { relationship }\end{array}$ & $r=0.53$ & $P<0.01$ \\
$\begin{array}{c}\text { Existence of fibre-cancer disease } \\
\text { relationship }\end{array}$ & $r=0.20$ & $P>0.05$ \\
\hline
\end{tabular}

* Spearman's rho correlation coefficient was used for ordinal data. †Pearson's $r$ correlation coefficient was used for interval data. 
survey in another class were asked not to complete it again.

The Statistical Package for the Social Sciences (SPSS) computer software, version 6.0.1, was used to analyse the data. Survey data were entered directly into the statistical software by the researcher after data collection was complete. Belief scores were treated as interval data. Differences in belief scores between label users and nonusers were examined using multivariate analysis of variance, specifically Pillai's criterion ${ }^{26}$. The level of significance for all analyses was set at $P<0.05$.

\section{Results}

\section{Study sample}

Of the 553 students who participated in the survey (92\% response rate), $51.5 \%$ were male and $46.8 \%$ were female. Nine (1.6\%) did not specify their gender. The age
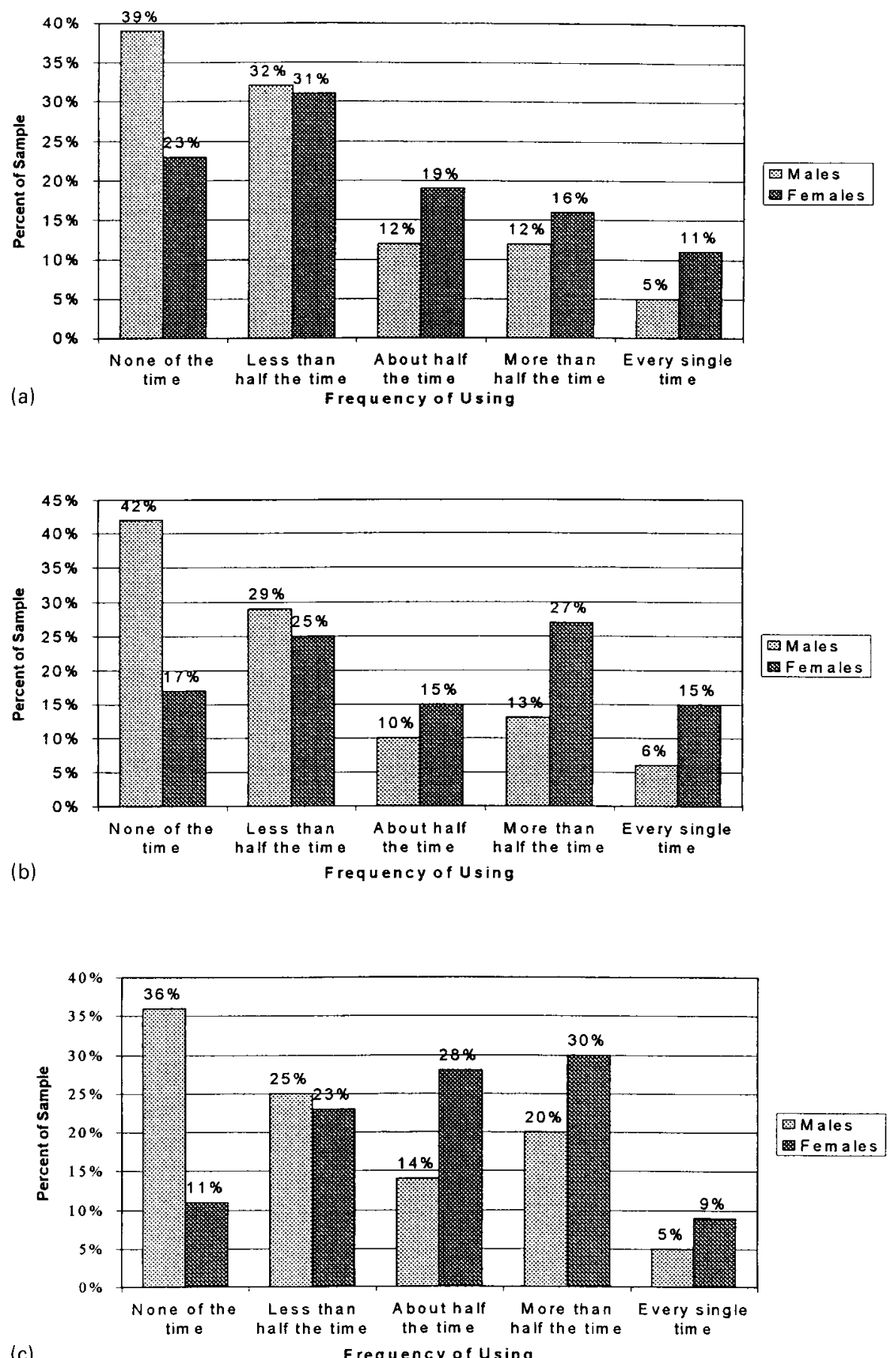

Fig. 1 Reported use of components of nutrition information on food labels: (a) ingredient list, (b) nutrition information panel, and (c) nutrient claims 
distribution of respondents was: $0.4 \%$ : $<18$ years, $44.1 \%$ : 18-20 years, 36.0\%: 21-24 years, 12.1\%: 25-34 years, $5.6 \%$ : $35-54$ years and $0.2 \%$ : $\geqslant 55$ years. Nine people (1.6\%) did not specify their age.

\section{Test-retest results}

Table 1 shows the reliability estimates for the questionnaire sections as determined by the test-retest surveys. These estimates provide a measure of the stability of responses to questionnaire items over a 2 -week period.

\section{Food label use}

Students were asked how often they used the ingredient list, the nutrition information panel and nutrient claims when purchasing a food product for the first time. Trends for the reported frequencies of using the different food label components differed between males and females. These trends are presented together in Fig. 1.

Based on the definitions of 'label user' and 'label nonuser', the proportion of label users to non-users in the study sample differed by gender. For males, there were roughly equal numbers of label users (48.6\%) and nonusers (51.4\%); whereas, for females, label users (78.8\%) outnumbered non-users $(21.2 \%)$ by nearly four to one. Because the distribution of label use was different between males and females, all analyses comparing users and non-users are reported separately by gender.

Not every respondent provided complete answers to all of the belief scales; therefore, the number of valid responses for a given belief are given in parentheses. Multivariate analysis indicated that there were significant differences between label users and non-users when all dependent variables were considered together. Therefore, individual F-tests were used to examine where these differences resided. Table 2 summarizes mean score and significance levels for differences in beliefs about nutrition information on food labels and diet-disease relationships.

The mean belief score for the entire sample on the importance of nutrition information on food labels in making food choices belief was $3.81(n=537)$. This score is best represented by the item 'Nutrition information on food labels plays a small but significant role in influencing my food purchase decisions'. Differences between label users and non-users on this belief were significant for both males and females. Label users scored higher on this belief than did non-users for both gender groups.

The mean belief score for the truthfulness of the nutrition information panel was $3.70 \quad(n=542)$. A compromise between the following two items best represents this score: 'The nutrition information panel is a somewhat believable source of information about the nutrient content of a food' and 'The nutrition information panel can be trusted most of the time as a source of truthful information about a food's nutrient content'. Male label users scored significantly higher on this belief than did male non-users. There was no significant difference between female users and non-users for scores on this belief.

The mean belief score for the truthfulness of nutrient claims was $3.40(n=539)$. The mean belief score for this belief lies just above the scale value for the statement 'It's difficult to tell if nutrient claims on food packages are true or not'. Mean scores for label users and non-users did not differ significantly for either males or females on the belief that nutrient claims are truthful.

The mean belief score for the existence of a relationship between dietary fat and heart disease was $5.01(n=539)$. The mean belief score lies above the scale value for the item 'Eating a low-fat diet may help protect you from developing heart disease' but below the scale value for the item 'Eating a low-fat diet is an effective way to reduce your risk of developing heart disease'. The difference between male label users and non-users on this belief approached significance. No significant difference was found between these scores for females.

The mean belief score for the existence of a relationship between dietary fibre and cancer was 3.65 $(n=525)$. The mean score lies just below the scale value for the statement 'Cancers are not totally prevented by eating a fibre-rich diet'. The difference between male label users and non-users on this belief was significant.

Table 2 Belief scores and significance levels for beliefs about nutrition information on food labels and diet-disease relationships

\begin{tabular}{|c|c|c|c|c|}
\hline \multirow[b]{3}{*}{ Belief } & \multicolumn{4}{|c|}{ Belief scores } \\
\hline & \multicolumn{2}{|c|}{ Males } & \multicolumn{2}{|c|}{ Females } \\
\hline & $\begin{array}{l}\text { Label } \\
\text { users }\end{array}$ & $\begin{array}{l}\text { Label } \\
\text { non-users }\end{array}$ & $\begin{array}{l}\text { Label } \\
\text { users }\end{array}$ & $\begin{array}{l}\text { Label } \\
\text { non-users }\end{array}$ \\
\hline $\begin{array}{l}\text { Importance of nutrition information on food labels } \\
\text { when making food choices }\end{array}$ & $4.17^{*}$ & $3.13^{*}$ & $4.11^{*}$ & $3.39^{*}$ \\
\hline Truthfulness of nutrition information panel & $3.83^{*}$ & $3.48^{*}$ & 3.80 & 3.59 \\
\hline Truthfulness of nutrient claims & 3.49 & 3.38 & 3.42 & 3.22 \\
\hline $\begin{array}{l}\text { Existence of relationship between fat and } \\
\text { heart disease }\end{array}$ & 5.06 & 4.90 & 5.07 & 5.06 \\
\hline Existence of relationship between fibre and cancer & $3.71^{*}$ & $3.49^{*}$ & 3.75 & 3.50 \\
\hline
\end{tabular}


No significant difference was found between these scores for females.

\section{Discussion}

The population from which the present study sample was drawn was students enrolled in second year classes in the College of Arts and Science at the University of Saskatchewan. The composition of these classes is varied. Degrees granted by other colleges and academic departments on campus frequently require that students take second year classes offered by the College of Arts and Science; therefore, students in other colleges participated in the present study. In addition, respondents were not always in their second year at university due to scheduling arrangements. Results of the present study may, therefore, apply to students from other colleges and other years at university. Due to the high response rate, the problem of non-response bias is unlikely to interfere with the interpretation of results from this study.

Label users outnumbered non-users by almost two to one in the university sample studied. These results compare similarly to label use estimates derived from other Canadian adult populations as shown in Table $3^{6-9}$. Canadians aged 18-34 years have been found to place less importance on nutrition than older age groups ${ }^{9}$, leading one to expect that students might use food labels less often than the average Canadian adult. However, university students are more educated than the general population and research indicates that individuals with at least some post-secondary education are more likely to use food labels than those without ${ }^{10,11,27,28}$.

Of the three label components that carry nutrition information, the nutrition information panel was used most frequently by the study sample; slightly fewer individuals used nutrient claims and even fewer used the ingredient list. These results differ slightly from the reported use of food label components by a Canadian adult population in 1991 in which the ingredient list was used most frequently followed by nutrient claims and the nutrition information panel $^{6}$. It may be that more nutrient claims are being made now than in 1991, when the study was conducted, providing more opportunity for their use. In previous years, concern about preservatives and chemical residues in or on food was approximately $10 \%$ higher than it is presently? This concern may have motivated consumers to read the ingredient list more often. The latest Tracking Nutrition Trends survey found that what currently concerns Canadians the most are fat content (79\% concerned) and vitamin content $\left(70 \%\right.$ concerned) in the $\operatorname{diet}^{9}$. To obtain information on the food label regarding these nutrition-related concerns requires examination of nutrient claims and the nutrition information panel, rather than the ingredient list. In addition, there are now many claims about preservatives on the front of food packages that may eliminate the need to refer to the ingredient list for this information. This may help explain why consumers are using the ingredient list less often. The use of specific food label components by this university population is consistent with the nutritional concerns of Canadian adults today.

Females consistently use each component carrying nutrition information more often than males. These results are consistent with those found in the literature ${ }^{6,9-11,27}$. It has been suggested that females use food labels more often than men because gender roles encourage them to place more importance on food selection ${ }^{11}$. Females may use food labels more often than males simply because they are the primary food purchaser: $85 \%$ of main grocery shoppers in Canada are female ${ }^{29}$.

The present study measured how respondents rated the importance of nutrition in making food choices using an

Table 3 Published estimates of food label use

\begin{tabular}{|c|c|c|c|c|}
\hline Sample & Gender & Age range & $\begin{array}{l}\text { Food label } \\
\quad \text { use }\end{array}$ & Reference \\
\hline $\begin{array}{l}\text { Probability sample representative of households in continental } \\
\text { USA }(n=4250)\end{array}$ & Not given & Not given & $45 \%{ }^{*}$ & Wang et al. (1995) ${ }^{5}$ \\
\hline Principal grocery buyers in five cities across Canada $(n=819)$ & $\begin{array}{l}20 \% \text { male } \\
80 \% \text { female }\end{array}$ & $20-70$ years & $64 \%$ & $\begin{array}{l}\text { National Institute } \\
\text { of Nutrition (1992) }\end{array}$ \\
\hline National randomly selected sample of Canadian adults $(n=1855)$ & $\begin{array}{l}48 \% \text { male } \\
52 \% \text { female }\end{array}$ & $\geqslant 18$ years & $61 \%$ & Beggs et al. $(1993)^{7}$ \\
\hline National probability sample of adult Canadians $(n=1902)$ & $\begin{array}{l}49 \% \text { male } \\
51 \% \text { female }\end{array}$ & $\geqslant 18$ years & $75 \%$ & Reid et al. $(1996)^{8}$ \\
\hline National probability sample of adult Canadians $(n=1956)$ & $\begin{array}{l}49 \% \text { male } \\
51 \% \text { female }\end{array}$ & $\geqslant 18$ years & $71 \%$ & $\begin{array}{l}\text { National Institute } \\
\text { of Nutrition (1997) }\end{array}$ \\
\hline $\begin{array}{l}\text { National probability sample of households in continental } \\
\text { United States }(n=400)\end{array}$ & Not given & Not given & $85 \%$ & Bender \& Derby $(1992)^{10}$ \\
\hline $\begin{array}{l}\text { Main meal planners/preparers of a probability sample of } \\
\text { households in continental USA with an } \\
\text { oversampling of low income households }(n=1906)\end{array}$ & Not given & Not given & $71 \%$ & Guthrie et al. (1995) ${ }^{11}$ \\
\hline $\begin{array}{l}\text { Students enrolled in second year classes offered by the College } \\
\text { of Arts and Science at the University of Saskatchewan }(n=553)\end{array}$ & $\begin{array}{l}52 \% \text { male } \\
48 \% \text { female }\end{array}$ & $\geqslant 18$ years & $63 \%$ & $\begin{array}{l}\text { Present } \\
\text { study }\end{array}$ \\
\hline
\end{tabular}

${ }^{*}$ Respondents were asked if they use food labels specifically for nutritional reasons as opposed to other studies where the reason for using food labels was not asked. 
interval scale, unlike previous research that has used primarily Likert-type and qualitative scales. Therefore, a direct comparison can not be made between the perceived importance of nutrition information measured in the present study and that measured in other studies. In the general adult Canadian population, $65 \%$ consider nutrition to be 'extremely' or 'very' important ${ }^{9}$. However, university students appear to place less importance on nutrition information on food labels believing, on average, that nutrition information on food labels plays a small but significant role in influencing food purchase decisions. This is consistent with previous research where young adults and adults without children have been found to ascribe less importance to nutrition when making food choices than do older adults and adults with children ${ }^{8,9,28,30}$.

No previous research has reported examining food label use in relation to the belief that nutrition is important in making food choices. As was expected, more label users believed that nutrition information is important in making food choices than label non-users for both males and females. Those who consider nutrition important in selecting foods may have specific dietary concerns. They may be trying to limit their intake of total fat or certain kinds of fat, obtain adequate amounts of vitamins and minerals, increase fibre consumption and/or watch their energy intake. In order to follow any type of self-initiated or prescribed dietary pattern, reading the nutrition information provided on food labels is important. This group may also have a general interest in nutrition that motivates them to read labels to learn more about the nutrient content of foods.

Distrust of the nutrition information panel appears to be a barrier for young men in using food labels but not for women. If presented with nutrition information that is perceived to be untrue, males reported that they would not use the information, whereas females reported that they would use it. The greater social pressure to eat a healthy diet that young women experience ${ }^{31}$ may encourage them to take actions towards achieving such objectives, even when they do not have faith in those actions. Alternatively, it could have been that there were too few female non-users to detect an actual significant difference.

Belief in the truthfulness of nutrient claims is not significantly associated with food label use for either males or females: food labels are used regardless of the perceived credibility of nutrient claims. The nutrition information panel has been shown to be distrusted by fewer individuals (5\%) than nutrient claims $(51 \%)^{6}$. Thus, it is reasonable to suppose that when students question the accuracy of a nutrient claim they turn to the nutrition information panel to verify it; therefore, distrust of nutrient claims may simply result in other parts of the food label being used instead.

Believing that relationships between diet and health (i.e. fat and heart disease; fibre and cancer) exist was more associated with food label use among males than females. These results again point to the suggestion that males use food labels more purposefully than do females in that males report looking for nutrition information when they are aware of diet-disease relationships, whereas females report looking for nutrition information regardless of their awareness of such relationships. Again, the proportionately small number of female non-users could have prevented the detection of a true relationship between belief of diet-disease relationships and food label use.

Due to the cross-sectional nature of the study, no causal inferences can be made about the directionality of influence between beliefs and food label use. Furthermore, the cluster sampling technique used to obtain the study sample results in decreased precision of the statistics used due to decreased independent selections in the sample ${ }^{32,33}$. The overall response rate was 92\%; however, a degree of non-response bias may have affected the survey data, not as a result of students choosing not to participate in the study but, rather, more as a result of which professors permitted the researcher access to his or her classroom. Of 25 professors approached, eight (32\%) declined the survey request. Those professors who agreed to participate in the survey may have had a more positive attitude towards participating in research or towards health issues, which may have been reflected by their students.

For belief item selection, the research did not explicitly attempt to satisfy the criterion of irrelevance. Therefore, it is possible that the judge's personal beliefs and attitudes toward the information on food labels and diet-disease relationships may have influenced how they rated the belief items. Despite the fact that belief item selection was carried out using established procedures, reliability of some of the belief scales was determined to be below an acceptable level. Specifically, results pertaining to beliefs about the importance of nutrition information on food labels in making food choices and diet-disease relationships must be interpreted carefully. Possible explanations for instability of responses and, thus, low test-retest correlation exist. Being asked about the existence of dietdisease relationships on the first test may have caused respondents to think about and reconsider their beliefs regarding such relationships and, hence, change their responses on the retest. Under some conditions, mere thought about an issue can lead to polarization of the belief resulting in favourable beliefs becoming more favourable and unfavourable beliefs becoming even less favourable ${ }^{34}$. It could be that beliefs about food labels and diet-disease relationships are weakly held and thus may fluctuate over time. In addition, events external to the survey such as media coverage or public education campaigns focusing on diet-disease relationships or food label use may have altered participants' responses between the two surveys.

Even though the questionnaire items designed to assess 
the frequency of using information on food labels showed good reliability, it is possible that measured food label use was greater than actual food label use. Self-reporting of such behaviours is inherently prone to social desirability bias, where individuals overreport or underreport their behaviour so that it more closely reflects what they think the researcher expects. In addition, no information was collected on the use of the nutrition information on food labels for specific nutrients (i.e. fat, calories, etc.).

The present results suggest that there are opportunities to increase use of the food label as a tool for selecting a healthy diet by targeting specific groups with tailored health messages. The message that nutrition and diet affect health and, thus, should be an important consideration in making food choices should continue to be promoted to both males and females. Social marketing strategies that promote more immediate benefits of choosing a healthy diet, such as improved athletic performance, could be used to make the nutrition information on labels more relevant to young adults. It may be useful to begin providing nutrition education, specifically the impact dietary intake has on overall health and well-being, to all students at the high school level to encourage the adoption of healthy food choices as soon as they become responsible for their own food purchases.

Students, especially males, would benefit from knowing that the nutrition information panel is a credible source of nutrition information since those who disbelieve it are less likely to use labels. Even among label users, mean belief scores on the truthfulness of the nutrition information panel indicate that the nutrition information panel is far from being trusted. Nutrient claims were trusted even less than the nutrition information panel. Canadian adults also harbour scepticism toward food label information ${ }^{6}$. Public message campaigns, either through the media or at pointof-purchase or both, to convey to consumers that nutrition food labelling is regulated by the government and is required by law to be truthful should be considered.

The high average scores for the belief that a relationship exists between fat and heart disease suggests that it is achievable to communicate to young adults the link between diet and disease. It should therefore be possible to provide the necessary information to students to increase their awareness of the link between fibre and cancer. Male students, especially, might use food labels more often if they were aware that there is a relationship between fibre and cancer. This points to the importance of education from an early age on the links between diet and health and the importance of choosing a healthy eating pattern for the prevention of chronic disease and enhancement of well-being.

The food label can be a useful tool to help Canadians choose foods with nutritional characteristics to minimize their risk of long-term diet-related diseases like heart disease and cancer. However, the ability to use the food label to lower disease risk requires basic knowledge in a variety of areas: dietary guidelines, significance of the nutrient content of foods, meanings of nutrient terms and claims, long-term impact of dietary choices and, of course, some degree of numeracy. The nutrition information panel provides precise nutrition information but it is unrealistic to expect Canadians to keep track of their own diet in as much detail. Reports repeatedly indicate that some Canadians demand detailed nutrition information on every food label in Canada, as occurs in the USA. To what extent would this benefit Canadians? It is unlikely that the immense amount of nutrient detail provided by such food label reform would be utilized to its fullest extent. In fact, it may add to the confusion already present among consumers. Efforts to maximize the utility of the existing food label as a tool for selecting a healthy diet should include education initiatives to reach individuals who may not have the skills to comprehend the nutrition information panel, such as those with low literacy and numeracy skills.

There is much scope for further research on food label use. For example, is there a tendency for individuals to overreport food label use? If so, is there a difference between males and females in overreporting? Further research might also include in-depth investigations into the reasons for not using food labels. This would provide useful information translatable into more effective nutrition education and intervention strategies for removing the barriers to label use. The possibility of using label identification or point-of-purchase assurance of authenticity to increase the credibility of the nutrition information on food labels should be explored.

\section{Acknowledgements}

The authors would like to thank Dr Al Yackulic and Dr Shawna Berenbaum at the University of Saskatchewan for their helpful discussions, and the students at the university who took part in the study. Receipt of the Rhea Ritchie and Helen McLeod Scholarships by Shannon Smith are gratefully acknowledged.

\section{References}

1 Statistics Canada. Age Standardized Mortality Rates by Selected Causes, by Sex [Online]. Available at http:// www.statcan.ca/english/Pgdb/People/Health/death.htm. 16 March 1998.

2 National Centre for Health Statistics. Report of Final Mortality Statistics, 1995. Monthly Vital Statistics Report, Vol. 45, No. 11, Suppl. 2, Table 7 [Online]. Available at http:// www.cdc.gov/nchswww/fastats/death.htm. 25 April 1998.

3 Health and Welfare Canada. Nutrition Recommendations. Ottawa: Minister of Supply and Services, 1990.

4 Keystone Centre. The Keystone National Policy Dialogue on Food, Nutrition, and Health. Final Report. Washington, DC: Keystone Centre, 1996.

5 Wang G, Fletcher SM, Carley DH. Consumer utilization of food labelling as a source of nutrition information. J. Consumer Aff. 1995; 29: 368-80. 
6 National Institute of Nutrition. Consumer Use and Understanding of Nutrition Information on Food Package Labels. Ottawa: National Institute of Nutrition, 1992.

7 Beggs L, Hendricks S, Schwartz NE, Biro K. Tracking nutrition trends: Canadians' attitudes, knowledge and behaviours regarding fat, fibre and cholesterol. J. Can. Diet. Assoc. 1993; 54: 21-5.

8 Reid DJ, Conrad SA, Hendricks SM. Tracking nutrition trends, 1989-1994: an update on Canadians' attitudes, knowledge and reported actions. Can. J. Public Health 1996; 87: 113-18.

9 National Institute of Nutrition. Tracking Nutrition Trends: 1989-1994-1997. Ottawa: National Institute of Nutrition, 1997.

10 Bender MM, Derby BM. Prevalence of reading nutrition and ingredient information on food labels among adult Americans: 1982-1988. J. Nutr. Educ. 1992; 24: 292-7.

11 Guthrie JF, Fox JJ, Cleveland LE, Welsh S. Who uses nutrition labelling, and what effect does label use have on diet quality? J. Nutr. Educ. 1995; 27: 163-72.

12 American Dietetic Association. 1997 Nutrition Trends Survey [Online]. Available at http://www.eatright.org/ press090397e.html. 15 March 1998.

13 Huang Y, Hoerr S, Song W. Breakfast is the lowest fat meal for young adult women. J. Nutr. Educ. 1997; 29: 184-8.

14 Fishbein M, Ajzen I. Understanding Attitudes and Predicting Social Behaviour. Englewood Cliffs, NJ: Prentice-Hall, 1980.

15 Ajzen I. Attitudes, Personality and Behavior. Stony Stratford, UK: Open University Press, 1988.

16 Schwartz NE. Nutritional knowledge, attitudes and practices of high school graduates. J. Am. Diet. Assoc. 1975; 66: 28-31.

17 Allard R, Mongeon M. Associations between knowledge, attitude and behaviour in a junior college population. Can. J. Public Health 1982; 73: 416-19.

18 Chery A, Sabry JH, Woolcott DM. Nutrition knowledge and misconceptions of university students: 1971 vs. 1984. J. Nutr. Educ. 1987; 19: 237-41.

19 Seymour M, Hoerr SL, Huang Y. Inappropriate dieting behaviours and related lifestyle factors in young adults: are college students different? J. Nutr. Educ. 1997; 29: 21-6.
20 Food and Drug Administration. Health and Diet Survey. Washington, DC: Centre for Food Safety and Applied Nutrition, Consumer Studies Branch, 1995.

21 Seashore RH, Hevner K. A time-saving device for the construction of attitude scales. J. Soc. Psychol. 1933; 4: 366-72.

22 Edwards A. Techniques of Attitude Scale Construction. New York: Appleton-Century-Crofts, 1957.

23 Torgerson W. Theory and Methods of Scaling. New York: John Wiley \& Sons, 1958.

24 Edwards A, Kenney KC. A comparison of the Thurstone and Likert techniques of attitude scale construction. In: Fishbein M, ed. Readings in Attitude Theory and Measurement. New York: John Wiley \& Sons, 1967; 249-56.

25 Fishbein M, Ajzen I. Belief, Attitude, Intention and Behavior: an Introduction to Theory and Research. Philippines: Addison-Wesley, 1975.

26 Bryman A, Cramer D. Quantitative Data Analysis with SPSS for Windows: a Guide for Social Scientists. New York: Routledge, 1997.

27 Schapira D, Kumar NB, Lyman GH, McMillan SC. The value of current nutrition information. Prev. Med. 1990; 19: 45-53.

28 Reid DJ, Hendricks S. Consumer awareness of nutrition information on food package labels. J. Can. Diet. Assoc. 1993; 54: 127-31.

29 Food and Consumer Products Manufacturers of Canada Consumerline Canada. Don Mills, Ontario, 1996.

30 Grocery Products Manufacturers of Canada. Grocery Attitudes of Canadians. Don Mills, Ontario, 1995.

31 Patterson RE, Kristal AR, Lynch JC, White E. Diet-cancer related beliefs, knowledge, norms and their relationship to healthful diets. J. Nutr. Educ. 1995; 27: 86-92.

32 Sudman S. Applied Sampling. New York: Academic Press, 1976.

33 Henry G. Practical Sampling. Applied Social Research Methods Series, Vol. 21. Newbury Park, CA: Sage Publications, 1990.

34 Wilson T, Hodges S. Attitudes as temporary constructs. In: Martin L, Tesser A, eds. The Construction of Social Judgements. Hillsdale: Lawrence Erlbaum, 1992; 37-61. 